\title{
Day Times Microgram per Milliliter per Meter Squared
}

National Cancer Institute

\section{Source}

National Cancer Institute. Day Times Microgram per Milliliter per Meter Squared. NCI

Thesaurus. Code C111172.

Days times micrograms per milliliter, divided by meters squared. 